\title{
The Application of Human Capital Efficiency Management towards the Increase of Performance and Competitiveness in an Enterprise Operating in the Field of Distribution Logistics
}

\author{
Alžbeta Kucharčíková \\ University of Žilina \\ Faculty of Management Science and Informatics \\ Department of Macro and Microeconomics \\ Slovak Republic \\ e-mail: Alzbeta.Kucharcikova@fri.uniza.sk
}

\author{
Martin Mičiak \\ University of Žilina \\ Faculty of Management Science and Informatics \\ Department of Macro and Microeconomics \\ Slovak Republic \\ e-mail: Martin.Miciak@fri.uniza.sk
}

\author{
DOI 10.17818/NM/2018/4SI.21 \\ UDK 005.33 \\ Review \\ Paper accepted: 28. 8. 2018
}

\section{Summary}

The article focuses on the description of human capital management, especially on its part related to efficiency of human capital. It connects this topic with the specific conditions of enterprises operating in distribution logistics. To fulfil the aim, methods of induction, deduction, summarising and application of research evidence were used. The point is to explain how human capital and efficient utilisation and investment in this intangible asset can contribute to enhanced performance and competitiveness of logistics enterprises.

\author{
KEY WORDS \\ human capital \\ human capital management \\ efficiency \\ distribution logistics
}

\section{INTRODUCTION}

Different enterprises or economies need to use and combine the available inputs for production of the output in their transformation process. In connection with the process of human capital, generated positive externalities are manifested as a higher level of population health, prevention of better health, lower crime, knowledge transfer between members of the household, higher level of knowledge of the population, higher level of innovation and technological progress, increased competitiveness countries, businesses, etc. If the company or economy wants to prosper, it is in their own interest to make the effort for the effective use of all available inputs. The same applies to the use of human capital as a production input. Recently, the corporate level looks at human capital as the asset, one of the components of the market value of the company and, together with the structural capital, as part of the intellectual capital. The aim of this article is to explain how human capital and efficient utilisation and investment in this intangible asset can contribute to enhanced performance and competitiveness of logistics enterprises. The central point is in finding the aspects of HCM and its role in a logistics enterprise. It is followed by explanation of efficiency concept within the $\mathrm{HCM}$. An integral part of the whole structure is the examination of links between the principles and activities of HCM and improvement of enterprise's performance and competitiveness.

\section{HUMAN CAPITAL AND HUMAN CAPITAL MANAGEMENT}

There are numerous definitions of human capital in the foreign professional literature. However, the key points of the theory can be found in the following statements. Baron and Armstrong base their theory of human capital on Davenport's definition which states that: "people possess innate abilities, behaviour and personal energy, and these elements create the human capital which they bring into their work" [1].

Fitz-enz describes human capital in business terms as a combination of these factors:

"the traits one brings to the job - intelligence, energy, a generally positive attitude, reliability, commitment, one's ability to learn - aptitude, imagination, creativity, one's motivation to share information and knowledge team spirit and goal orientation" [2].

Armstrong and Taylor add the definition of human capital according to Wright and McMahan who say that: "Each individual in the organisation has characteristics that comprise human capital. He/she also engages in the processing of information, interpretation and reaction to that information in making choices about how to feel and behave" [3]. Then the theory of human capital deals with how people in the organisation contribute with their knowledge, abilities and skills to the increase of organisation's capabilities, and with the importance of this contribution. Using the statements on $\mathrm{HC}$ from literature and combining them with relevant factors influencing this issue inside an enterprise or coming from the external environment, the model depicted in Figure 1 was constructed. It shows the human capital in two tiers - core competences and broader human capital. Research findings related to some of the parts will be stated later in the text. The model is helpful also for the explanation of $\mathrm{HC}$ investment in the following section.

The connection with the area of Human resource information systems (HRIS) is placed in the model with mutual 


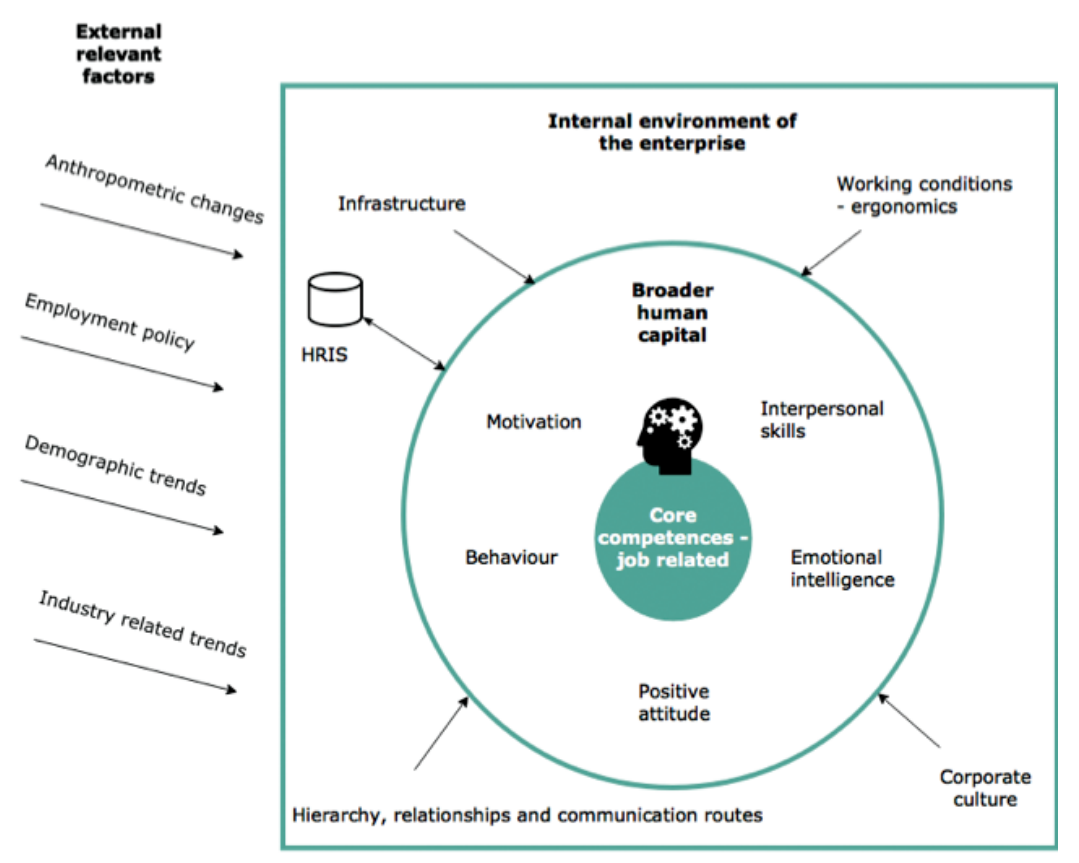

Source: authors

Figure $1 \mathrm{HC}$ in the context of internal and external environment of enterprises

relationship. This is because $\mathrm{HC}$ can be managed only if the appropriate data are being collected in the information system. But after the data are processed into information, informationbased decisions pertaining to $\mathrm{HC}$ influence its future state and development in the enterprise. Managerial "decisions require flexibility to respond to market demands, so managers need flexible information system with a high-quality information choice. Implemented financial controlling as a management tool in the company creates the basis for ensuring quality and effective management of corporate finance" [4].

In line with this opinion is the notion that people and many of their intangible attributes represent a valuable and indispensable form of capital for all kinds of enterprises, including those operating in the field of distribution logistics. Thus, also personal controlling should be implemented and integrated in the existing, often intricate, enterprise information system. Similarly to the data garnering, processing and interpretation via financial indicators, these activities pertaining to human capital can be performed within personal controlling to provide the necessary information support for efficient and effective performing of the whole variety of activities and decisions to be made. In connection to HRIS, even the term "human resources technology managers" is used. And Raffer says about them that: "at a time when workforce analytics are becoming critical to organizations' overall operations, they collaborate well with other departments that rely on people-based data to direct business decisions" [5].

\subsection{Human Capital Managemet and its Comparison with Human Resource Management}

To define human capital management (HCM), Armstrong and Taylor start with the description of The Accounting for People Task Force saying that HCM include systematic analysis, measurement and evaluation of how policies and practice concerning people create value. According to authors, the defining characteristic of HCM is the use of metrics for guidance of approach to people management, which considers them to be assets. They also emphasise that the competitive advantage is gained through strategic investment into these assets. This includes the increasing importance of employee engagement and retention, talent management activities, and programmes of learning and development. HCM connects HR strategy with the business strategy [3]. To differentiate HCM from human resource management (HRM), Armstrong summarises some of the specific HCM features. Here belong:

- focusing on the connection between HR interventions and success of organisation,

- strengthening of the belief that people are rather assets than just costs for the organisation,

HRM strategies and processes in the concept of HCM need to be based on the value creation through people and their abilities,

- HCM initiatives must be designed and implemented strategically,

- HR specialists need to become partners in the top-level management decision making,

HCM shows what needs to be measured and how it should be done,

- the main purpose of such measurement is to prove that excellent people management brings excellent results, and to set the direction for the next HR strategy.

To draw up conclusion from this comparison, Armstrong says that HCM supplements the concept of HRM, it does not substitute it. HCM and HRM could be seen as two necessary components combining their activities and results in the complex process of people management [6], [7].

\subsection{Human capital investment - Ergonomic workplace and anthropometric data}

Within the concept of $\mathrm{HC}$ and $\mathrm{HCM}$, not only its components are important, but also the investment into these components needs to be defined and managed. The investment into human 
capital consists of all financial and other resources used to extend the elements of human capital in the organisation. But it also includes the efforts to increase the utilisation of these important assets, and the interventions done to increase their life span - the period of time they are useable and effective. This corresponds with Becker's defining of human capital investment. He states that: "expenditures on education, training, medical care, etc., are investments in capital. However, these produce human, not physical or financial, capital because you cannot separate a person from his or her knowledge, skills, health, or values the way it is possible to move financial and physical assets while the owner stays put" [8]. He adds that education activities and training are the most important investments into human capital. Thus, the human capital investment can be categorised as follows:

expenditure and use of other resources dedicated to educational activities and training,

expenditure used to maintain the good health of employees, expenditure used to create and maintain suitable work conditions, good physical environment in combination with positive and pleasant corporate culture and climate.

The physical environment relates to ergonomics at work. Ergonomic workplace is a prerequisite also for the full utilisation of human capital. If this is taken from the industry perspective, logistics and operations that need to be performed by employees here on a daily basis are often hard physical work. The drivers need to sit in the vehicle for a long time. Since people are those who actually possess all the intangible qualities described above, they also need appropriate physical conditions and ergonomic work tools in order to be able to do their job for many years. And only if they can do so, they will be able to enhance and increase their knowledge and skills, and will be long-term assets for the enterprise.

Ergonomics is closely connected to the anthropometric data and changes in them as well. People living and working in this modern world have different conditions, and the requirements being put on them at work eventually change their bodies over time. Plus, the workforce of enterprises usually consists of various age groups - people from various generations. This makes it important for enterprises to pay attention to issues of anthropometrics, if they want to gain maximum from the potential of their employees.

\section{EFFICIENCY - PERFORMANCE - COMPETITIVENESS}

The complexity of human capital topic outlined in the previous sections is summarised and linked with the issues of efficiency in statements of Russ [9]. According to him, the knowledge represents a unique production factor which is now becoming the main factor in the global economy. The knowledge-based economy is characterised by a number of trends influencing also the measurement and evaluation of human capital, which is still more and more important under such conditions. These trends include the changing characteristics of workforce, experimenting with new organisation structures, emphasis on customer relationships, rapid innovations, and strong global competition. A crucial factor of sustainable capability and competitiveness is the ability to attract, develop and retain the talent and human capital. Efficient and effective deployment and engagement of human assets is now commonly recognised feature of prosperous enterprises.

Within the HCM, it is needed to measure and evaluate efficiency and effectiveness into two dimensions. One of them is efficient utilisation of the current human capital. The other one is evaluation of efficiency of investment realised into this asset. Some of the basic (overall) metrics for human capital are shown in the human capital scorecard further in the text. Investment in people development is usually being evaluated using modifications of ROI (return on investment) method. It represents a starting point in HCM measuring initiatives. More sophisticated methods can be used to incorporate the perspective of present value of money, or to add the element of risk which influences all kinds of investment. However, both these dimensions of efficiency evaluation within HCM work on the assumption that specific HC components important in a specific industry or enterprise are identified. In addition, human capital and its investment can be effective only if both are linked to certain measures of performance - KPIs (key performance indicators) applicable for the selected industry or enterprise. To emphasise the importance of efficiency evaluation within $\mathrm{HCM}$, giving the purpose of all measuring activities, human capital efficiency management (HCEM) can be established. It can represent the attempts to not only measure the human capital, but to reveal connections leading from good results in utilisation and investment in human capital to the increased performance and competitiveness (Figure 2).

Some tools and approaches of HCM, research findings and connections of $\mathrm{HC}$ elements and investment with the industry of logistics are included in the following sections.

\subsection{HCM tools and approaches}

Human capital scorecard was created to adapt a popular balanced scorecard logic for specific needs of human capital management. Human capital scorecard, being based on the logic of balanced scorecard, covers all the fundamental activities in human capital management [2]. They represent the four quadrants in it. The planning part is above the scorecard itself, creating the necessary precondition for the activities and measurements in the scorecard. FTE stands for full time equivalent, which helps to summarise and compare employees working on full time with those working on part time and those working for an enterprise through an employment agency. In this example, sample metrics for the utilisation of human capital are shown, categorised according to individual human capital management activities. To make this method thorough, each quadrant should include measures of cost, time, quality and quantity. The lower base represents factors of reactions. Attitudes and behaviours of employees are not only a component of human capital, but it is also beneficial to study the reactions of employees on human capital policies and their practical application.

\subsection{Ingham's value matrix}

According to Ingham [10], the true HCM exists only there where the value is not just being added by suitable people management, but where the value itself is being created by individual HCM activities and their interconnections. He describes this concept through the value matrix, which is the result of combining the value triangle with the value chain. The top level in the value triangle is represented by HCM, positioned 


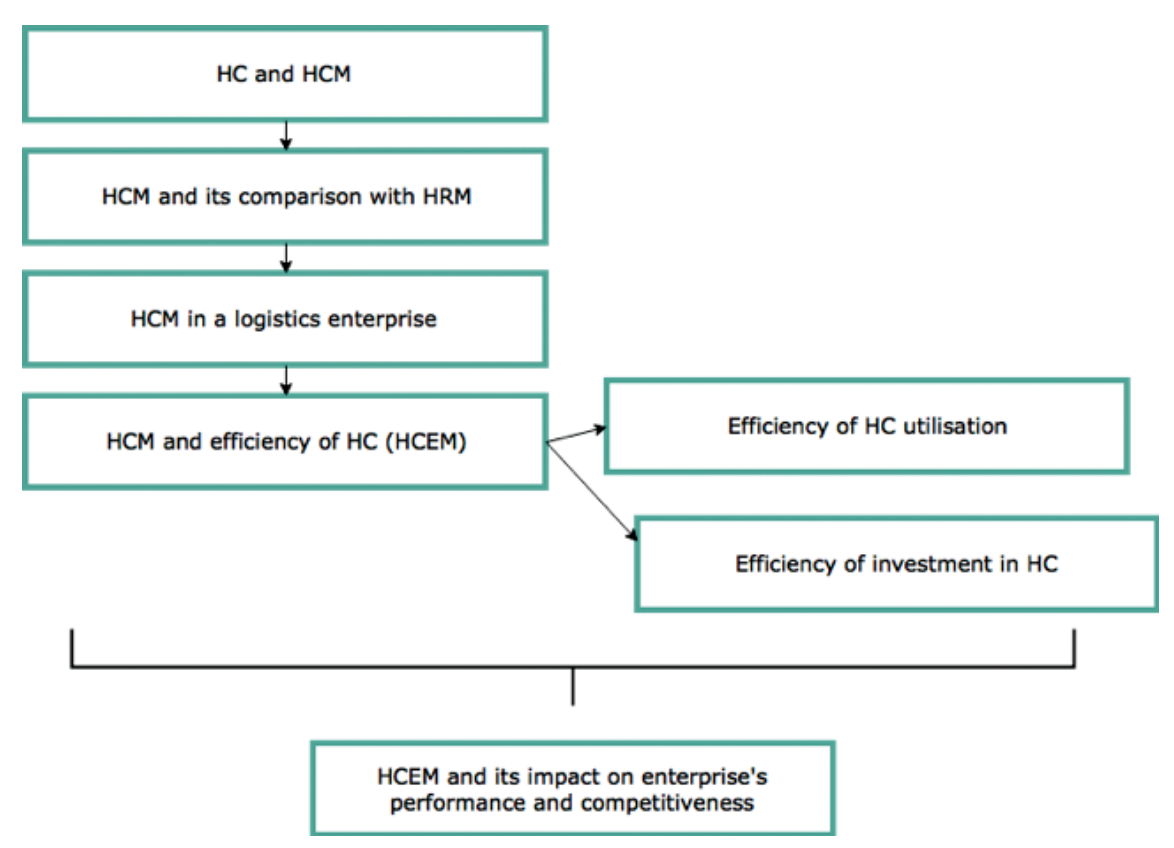

Source: authors

Figure 2 Impact of HCEM on enterprise competitiveness

above human resource management. The author also states that when enterprises implement HCM, they do not apply the best practices from the field of people management, but they look for best fit practices. So, the attention is paid to the specifics of the unique setting and environment. In this case, it is the environment of distribution logistics. Industry can embody important factors, limitations but also opportunities also for the HCM that is desired to be implemented. Some best practices bringing positive results in one industry or group of enterprises do not have to result in the same effects in another. Best fit practices are also connected to the overall business strategy of an enterprise. This emphasises the fact that if the development of people, of their intangible capabilities representing an important asset, is isolated from the business strategy, it will never bring actual, and eventually even tangible, value. Under such circumstances, however elaborate it can be, it will not be truly helpful for the enterprise. And once investment in this area disappoints those in enterprise who allocate funds, the HCM people will have difficulties with getting the resources needed for their next activities.

\subsection{HCM analysis by McBassi \& Company}

Dealing with the HCM analysis within an organisation operating in distribution logistics makes sense. As a tool to do so, appropriate questions can be designed and used in employees' surveys. Then these surveys need to be conducted regularly. The questions can be divided into several main categories. The McBassi \& Company suggests the division into these five categories - leadership practices, employee engagement, knowledge accessibility, workforce optimisation, learning capacity [11]. Within the selected categories, the occurrence of best practices (or when combined with Ingham's recommendation - best fitting practices) proven by research works can be tested. And through this, the operation of the $\mathrm{HMC}$ in an enterprise can be periodically reassessed. Score can be calculated for individual categories as well as for the HCM as a whole. When adjusted for specific conditions, in this case for the conditions of distribution logistics, both important financial and non-financial outcomes can be predicted using the scores of HCM categories and driving factors. To do so, specific KPIs for logistics need to be selected and defined. Also, HCM categories need to be organised, making it possible to collect the data needed for subsequent analytic processing. Useful analytic tools and calculation can reveal valuable knowledge in the form of patterns and connections among HCM categories and their scores within an enterprise for one period in time, and relevant KPIs in the following period. This is related to studying the correlations, creating regression models and testing them for their use in making predictions. When such activities are successful, enterprises can find out which HCM categories influence which performance measures, plus the strength of these influences. The fact that the identified patterns can change over time shall not be forgotten. That is why HCM analysis requires systematic and long-term efforts. The connection to relevant logistic KPIs makes this issue a specific use of HCM principles in the field of logistics.

Since the HCM agenda requires long-term perspective, it is often denoted as strategic. Thus, HCM elements should be entrenched even in the vision itself. When it is the case of logistic enterprises, they can strive to be the best place for work in logistics. This way such enterprise can attract truly valuable talent, embodied in the best people in terms of logistics education, experience, but also those with the true enthusiasm for this field. The strategic part of the issue also means that the strategy developed for HCM needs to be linked and aligned with those of other functional areas in enterprise.

Another point pertaining to the human capital emerges from the above-mentioned analytical work necessary for extraction of useful information from the HCM data. HR specialists and executives need sufficient level of knowledge and skills both connected to HC theory and to analytics and their possibilities of use. The loop closes when for an enterprise to be able to use the human capital in an efficient way, it needs to acquire or develop certain knowledge and skill set directly 
related to the concepts, activities and analytical part of HCM. This includes analytical skills, skills in using statistical software, plus understanding and open-mindedness when it comes to possible links between HCM and organisational performance.

\section{4. $\mathrm{HCM}$ in an enterprise operating in distribution logistics}

Distribution logistics is the part of economic activity focused on the transport of final product to its customer. Its activities are organised around efficient distribution and movement of finished products. It is about getting the goods being produced in production lines to their consumers. Some connections of $\mathrm{HCM}$ and logistics were already described in the previous part, but they need to be explained more deeply and accompanied by relevant outputs of research activities. In the field of logistics, the performance is described by the throughput time of the process, transaction efficiency and reliability, or by timely and accurate external and internal exchange of information. Performance standards within the supply chains are expressed using KPIs such as delivery in full (DIF), delivery on time (DOT), or delivery in full on time (DIFOT). Costs of the logistics process are important as well. Another indicator is represented by inventory stock turn in days. Distribution logistics include also the transportation management. The efficiency is being achieved here by high utilisation of the database of partner carriers. Enterprises are looking for the optimal transportation approach in terms of their business. The priority lies on outbound, inbound and internal transportation. Logistics enterprises need to ensure stability, visibility and control of transportation costs and functions for their clients. The improvement here, which can be gained just through HCM and its efficiency, should bring transportation optimisation, high quality of service and overall cost reduction.

The relationship between human capital management and business results is the object of various research works and of many initiatives of consulting companies or the enterprises themselves. However, if this relationship is meant to be properly examined, it is necessary to pay attention to both sides of the equation. An enterprise needs to adopt a fitting implementation of HCM to cover its distinctive features and specifically important components of its human capital as an intangible asset. But, it also must clarify how it is going to monitor its performance, and what measures and indicators will be the most suitable for this. "Enterprises are currently trying to bring new technologies into production and use new procedures and recommendations in various management activities. However, they should not forget to change their approach to the evaluation of the results achieved, and focus on the use of modern methods of performance evaluation" [12].

Following the model of human capital with internal and external context, there are specific knowledge and skills the people in logistics enterprises need to acquire, and there are also industry-specific trends coming from outside of enterprises. The latest technology advances in distribution logistics brought augmented reality and its forms of use in dispatching - pick by voice or pick by vision. Another significant trend is green logistics which, if implemented the right way, can contribute to the competitive advantage on the markets where customers are still more and more aware of the necessity to protect the nature. In relation to this, there was a research conducted, focusing on the strategy of green marketing as a source of competitive advantage for companies operating in the value-supply chain of the automotive industry in Slovakia. The content analysis of their activities related to the implementation of green marketing principles was performed. Results revealed also that "there is a statistically significant relationship between the implementation of the principles of green marketing and the competitive position of the business on the market and its overall competitiveness" [13]. "In difficult economic conditions, only the strongest enterprises will survive, so the issues of competition and competitiveness are actual and encourage the current pressure on controlling costs in enterprise in order to maintain competitive advantage" [14]. These costs include also the costs related to human capital of an enterprise, and those related to its development. One way of becoming competitive on the market and maintaining this competitive advantage is through the efficient human capital management. Competitive advantage gained this way is considered to be very difficult for competitors to imitate, since useful knowledge, professional skills, appropriate attitudes and behaviour of employees is not something that can be acquired easily. It requires designing, implementing and systematically practising the strategic human capital principles interconnected with all other parts of management and operation of enterprises.

Based on the points from human capital theory and management, the following research findings fit into the $\mathrm{HC}$ model in the context of logistics enterprises and their higher performance and competitiveness. They are categorised according to their character. "Currently, businesses apply unified motivational programs, based on two, three, or four main motivators. However, improperly designed and applied motivational programs have a negative impact on employees and do not motivate them to maximise performance" [15]. Motivation is an element that is being taken care of in HRM where HR specialists look for means and ways how to motivate all the employees so that they deliver their best performance within their functions and positions. But, it also intersects with the scope of HCM, since only motivated employees can efficiently use their abilities, knowledge and experience in their everyday work. Motivational programmes and tools should not omit the incentives leading to the willingness and aspiration for further development of one's components of human capital. Employees need to see that the enterprise supports and guides them to working on their skills and capabilities. Not that they are just required to deliver the work with desired quantity and quality every day. Getting the job done represents the orientation on the current state, whereas motivating to develop and extend employees' abilities bears the orientation on possible, better future results. HCM is more about the strategic perspective where HR data on motivation give important insight and base for decision making influencing future operation and capability of the whole enterprise.

The research conducted in motivation preferences of employees found out significantly different preferences of motivation factors [16-19]. These findings reveal that motivational factors that bring results can have limitations in terms of their applicability for employees from different cultures and nationalities. This implies that diverse teams of people can bear advantages in the form of enhanced team dynamics, creativity and ability to generate new, unique solutions to 
problems, but it can be more difficult to motivate them. This also applies for enterprises that operate their functional units over boarders of countries, have their subsidiaries or functional units spread over larger areas - which is not unusual for enterprises in distribution logistics. They will probably need different motivational policies for different units so that they can fully utilise their human capital assets in all regions they operate in.

According to the literature sources covering the topic of $\mathrm{HC}$ and its management, this asset of enterprises is not only about competences of all groups of employees, it encompasses other relevant issues as well. Corporate culture, being one of them, gives all other aspects of human capital its foundation on which they interconnect and influence each other. Culture was identified in the model in the beginning of the article as one of internal influencing factors. Corporate, or organisational, culture concerns every industry. But, one particular study was conducted within the field of logistics in Slovakia. "Utilising the Organisational Culture Assessment Instrument (OCAl), we diagnosed the dominant trend within Slovak logistics enterprises. Overall these enterprises have a hierarchical organisational culture. However, employees are of the opinion that there should be a more familial work environment, typical of a clan organisational culture" [20]. This means that HR specialists and HCM managers need to examine, assess and positively change the culture in logistics enterprises in order to prepare the best possible conditions for other elements of human capital to exist and develop in.

Another research work was conducted specifically for motivation and the factors influencing it among employees working for enterprises in logistics and transport. This study was also focused on the differences or similarities in motivation factors comparing a sample from the Czech Republic and from one part of the PRC. The authors state that: "we can see which group of motivation factors most influences employees of transporting and logistic companies and their work performance in the Czech Republic and in the region in Bejing. The highest stress is put on the relational motivation factors in both the nationalities. We can therefore state that both the nationalities improve the work performance if they feel good at the workplace, have good relationship with their colleagues and their superiors are a support to them" [21]. This provides some useful guidance for HCM of enterprises operating in logistics, showing the managers where to put the emphasis when devising and implementing motivational policies.

It was revealed that: "Most employees of the Slovak enterprises perceived the changes as a negative feature during the Global Economic Crisis. Currently, during the time of the economic growth, two thirds of them perceive the changes rather as the opportunities than the threats" [22].
Positive relation to changes can be viewed as desirable, since it makes enterprises more flexible as a whole, and make all the employees more open to new concepts the management is about to implement, and to new pieces of information and knowledge coming both from internal development activities and from the trends in external environment.

\subsection{The design and verification of metrics for the assessment of efficiency in the transport and logistics enterprise "ETL" in HCM context - an example from the practice}

The design of the metrics for the assessment of the human capital efficiency in the ETL enterprise deals with the identification of the key performance and the key knowledge, skills and abilities of the workforce in the ETL enterprise. Based on the identification, the indicators are designed with the aim to reveal the efficiency of the utilisation of human capital $(\mathrm{HC})$ and the efficiency of the investment in $\mathrm{HC}$. It is necessary to make the metrics focused on the specific conditions in the enterprise and on the factors influencing it.

A key performance indicator within human capital in the case of the ETL enterprise is unequivocally represented by the revenues it generates. The metrics for the assessment of the efficiency of utilisation of $\mathrm{HC}$ need to be designed following the specific conditions of the enterprise. This means that the metric should be focused on concrete factors influencing the enterprise to the greatest extent. These mainly include the customers' complaints about the drivers' behaviour and the costs related to this, and also the tracking of the number of regular customers. The designed metric within the scope of the efficiency of the investment in $\mathrm{HC}$ is related to the training activities that would be a solution to the issue of the complaints about the inappropriate behaviour and unwillingness of drivers. The training activities were related to communication skills, aggression and stress management, and also to the language courses.

The costs related to the complaints are the costs caused by the customers' complaints about the drivers' behaviour and their resolving. The complaints were not only causing the loss of customers and financial costs, but they were also influencing the enterprise's reputation, which is considered to be the greatest issue. Since 2014, the enterprise has started performing motivational training activities with the aim to eliminate this problem.

We designed the metric:

$$
\mathrm{E} 1=\frac{\text { Costs related to the complaints }}{\text { Costs of the drivers' training }}
$$

The closer the value is to 1 the more efficient the investment activity is.

Table 1 The E1 metric for the assessment of the efficiency of investment in HC between 2010 and 2015

\begin{tabular}{|l|c|c|c|c|c|c|}
\hline & 2010 & 2011 & 2012 & 2013 & 2014 \\
\hline $\begin{array}{l}\text { Costs related to } \\
\text { the complaints }(€)\end{array}$ & 2125 & 1987 & 1429 & 958 & 235 \\
\hline $\begin{array}{l}\text { Costs of the } \\
\text { drivers' training }(€)\end{array}$ & 0 & 0 & 0 & 0 & 3495 \\
\hline E1 & - & - & - & - & 3600 \\
\hline
\end{tabular}

Source: own processing of the data from the internal materials of the ETL enterprise 
The stated facts show that the efficiency being assessed based on the designed metric E1 rises. In the case when the costs of the complaints' resolving exceed the costs of the drivers' training, the investment activities would be inefficient. There is also a possibility to be considered to compare the costs on the training in the time $t$ with the costs of the complaints in the time $t+1$, since the return on the investment has a lagged effect, i. e., the results of the knowledge gained via the training manifest themselves later in time. The investment activities oriented on $\mathrm{HC}$ have a long-term nature.

For the ETL enterprise, it is not only important to gain new customers and new contracts, but also to maintain the current and regular customers. The approach of the ETL enterprise's employees and the quality and timeliness of the services provided contribute to this significantly. As the second indicator of the $\mathrm{HC}$ efficiency in the ETL enterprise, we designed:

$$
\mathrm{E} 2=\frac{\text { Revenues gained from regular customers }}{\text { Revenues from logistics services }} * 100
$$

The E2 metric shows the percentage share of the revenues gained from regular customers (thus the satisfied customers) in the revenues from logistics services. The higher the value, the better the enterprise utilises the knowledge, abilities and skills of the drivers that then contribute to the revenues of the ETL enterprise. The value has a rising trend within the period between 2010 and 2015, which means that the efficiency of utilisation of $\mathrm{HC}$ rises.

The designed metrics are focused on the specific conditions of the ETL enterprise. This means that they deal with the factors influencing the economic results of the enterprise to a great extent, and the efficiency of human capital can be revealed via them. The metrics relate to the efficient utilisation of the drivers' $\mathrm{HC}$.

\subsection{Customer service and Cost management}

Team of authors examined the preferences of customers in connection with e-commerce and its logistics. The data were collected through questionnaire survey in 2015 in the Czech Republic. In the survey, 650 respondents were interviewed, obtaining 503 valid responses, while using the set of respondents representing the population of the Czech Republic. The research focused on buyers of goods using the options of electronic commerce. The results were: "segmenting customers into four clusters according to their preferences regarding logistics support and risk perceptions while shopping in e-shops was done to find out and outline a major group" [23]. Authors also state that: "The preferences of customers shopping in e-shops acquired due this research can be used as a basis for considering alternatives for the enterprise when deciding on the way of sales logistics. The data can be used for the so-called Knowledge Base in these information systems. By optimising the choice of elements of sales logistics, the costs can be more effective incurred with meeting customer requirements and thus, to obtain a satisfied customer having high potential of both current and future purchases" [23].

Higher competitiveness can be achieved by an enterprise in many, different ways [24-28]. One of them is to manage the costs better, more efficiently, to save significant portions of funds. "The market environment and tough competition generates pressure on companies to reduce their costs as much as possible. Numerous cost monitoring methods exist for cost management". These methods include, for example the $A B C$ Analysis. "ABC Analysis also helps to determine costs with regards to different calculation objects, not only products, but also for example, distribution routes, customers, services, etc.." Among the here mentioned, the distribution routes and costs related to them can be particularly interesting for enterprises in

Table 2 Efficiency of HC based on the designed metric E2 between 2010 and 2015

\begin{tabular}{|l|c|c|c|c|c|c|}
\hline $\begin{array}{l}\text { Revenues gained } \\
\text { from regular } \\
\text { customers }(€)\end{array}$ & 2010 & 2011 & 2012 & 2013 & 2014 & 8315 \\
\hline $\begin{array}{l}\text { Revenues from } \\
\text { logistics services }(€)\end{array}$ & 47925 & 83640 & 84950 & 84155 & 84110 & 83565 \\
\hline E2 (\%) & 1.57 & 528346 & 5330488 & 5217492 & 5105149 & 5040151 \\
\hline
\end{tabular}

Source: own processing of the data from the internal materials of the ETL enterprise

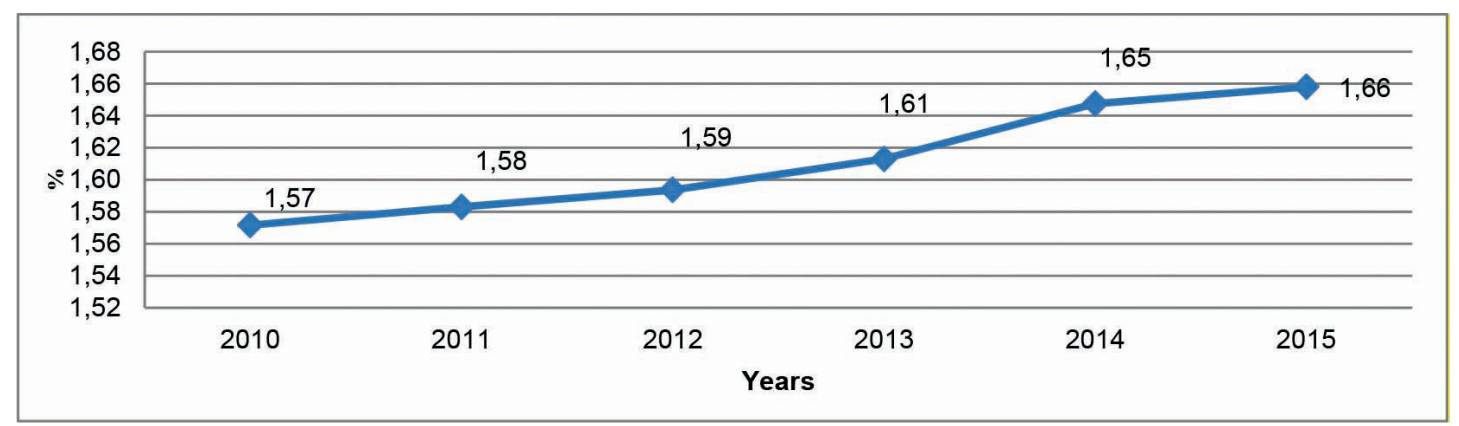

Source: own processing of the data from the internal materials of the ETL enterprise

Figure 3 The course of the efficiency of HC based on the designed metric E2 between 2010 and 2015 
the field of distribution logistics. So, the cost management, and the knowledge combined with practical skills in this discipline represent the possible focus of human capital investment in a logistic enterprise with the aim to help improve its performance and increase its competitiveness. If the responsible employees in the enterprise have such knowledge and skills at their disposal, they can think of ways how to perform these activities better, obtaining valuable and measureable benefits [25-29].

\section{CONCLUSION}

Human capital can be tracked down across all different functional areas and all work positions. It is an integral component of the complex system of enterprise's internal environment. This justifiably puts so much importance on it, its efficient utilisation and well-designed and executed investing in its further development. This article focused on the explanation of $\mathrm{HC}$ concept, HCM, and on the efficient and effective utilisation of human capital together with the efficient investment into its future development. The specific parts of this topic were examined from the perspective of enterprises operating in the field of distribution logistics. Various research evidences prove that this topic is current, and it is reasonable for logistic enterprises to pay enough attention to it. Creating an elaborated HCM for specific conditions is a way of achieving a continuous high performance and strong position among the competitors.

\section{Acknowledgements}

This article was created as part of application of project APVV16-0297 Updating of anthropometric database of Slovak population and project VEGA No 1/0652/16 Impact of spatial location and sectorial focus on the performance of businesses and their competitiveness in the global market.

\section{REFERENCES}

[1] Baron, A., Armstrong, M. Human Capital Management: Achieving Added Value through People. Kogan Page Publishers, 2007, 226 p. ISBN 9780749449384.

[2] Fitz-enz, J., ROI of Human Capital - Measuring the Economic Value of Employee Performance, AMACOM, 2009, 336 p. ISBN 978-0-8144-1332-6.

[3] Armstrong, M. a Taylor, S. 2014. Armstrong's Handbook of Human Resource Management Practice. Kogan Page Publishers. 2014. 880 p. ISBN 9780749469658.

[4] Chodasová, Z., Tekulová, Z. Monitoring of competitiveness indicators of the controlling enterprise. Scientific Publication of the International Conference on Engineering Science and Production Management, ESPM 2015, pp. 101106.

[5] Raffer, M. V., Plugging In: Technology Continues Its Surge through HR Departments. Workforce Magazine, 2018, [on-line], Available on: http:// www.workforce.com/2018/01/01/plugging-technology-continues-surge-hrdepartments/.

[6] Armstrong, M. 2006. A Handbook of Human Resource Management Practice. Kogan Page Publishers. 2006. 982 p. ISBN 9780749446314

[7] Torres-Coronas, T., Arias-Oliva, M. Encyclopedia of Human Resources Information Systems: Challenges in E-HRM, Vol. 1, Information Science Reference, 2008, 500 p. ISBN 9781599048833.
[8] Becker, G. S. 2009. Human Capital: A Theoretical and Empirical Analysis, with Special Reference to Education. University of Chicago Press. 2009. 412 p. ISBN 9780226041223.

[9] Russ, M. Quantitative Multidisciplinary Approaches in Human Capital and Asset Management. IGI Global. 2015. 318 p. ISBN 9781466696532.

[10] Ingham, J. Strategic Human Capital Management. Routledge. 2007. 400 p. ISBN 9781136363214

[11] Bassi L., McMurrer D., Human Capital and Organizational Performance: Next Generation Metrics as a Catalyst for Change, 2006, McBASSI\&Company White Paper, [on-line], Available on: http://mcbassi.net/resources/documents/ NextGenerationMetrics.pdf.

[12] Malichova, E., Durisova, M., Tokarcikova, E. Models of application economic value added in automotive company. Transport Problems, 2017, Vol. 12, No. 3, pp. 93-102.

[13] Moravcikova, D., Krizanova, A., Kliestikova, J., Rypakova, M., Green Marketing as the Source of the Competitive Advantage of the Business. Sustainability, 30 November 2017. https://doi.org/10.3390/su9122218

[14] Tekulová, Z., Králik, M., Chodasová, Z. Environmental policy enterprise as a competitive advantage. Smart City 3602016 - 2nd EAl International Summit, 14 February 2017, Bratislava; Slovakia.

[15] Hitka M., Lorincová S., Ližbetinová L., Bartáková Pajtinková G., Merková M. Cluster Analysis Used as the Strategic Advantage of Human Resource Management in Small and Medium-sized Enterprises in the Wood-Processing Industry. BioResources, 2017, Vol. 12, No. 4, pp. 7884-7897, ISSN 1930-2126.

[16] Hitka, M., Sedmák, R., Alác, P., Grladhovic, T. Establishment of motivation programs for workers in manufacturing companies using cluster analysis. Drvna Industrija, 2005, Vol. 56, No. 1, pp. 21-28. https://doi.org/10.5552/ drind.2014.1303

[17] Hitka, M., Sirotiakova, M. The impact of economic crisis on the change in motivation of furniture company employees - case study. Drewno, 2011, Vol. 54, No.185, pp. 119-126.

[18] Hitka, M., Hajdukova, A., Balazova, Z. Impact of economic crisis on changes in motivation of employees in woodworking industry. Drvna Industrija, 2014 Vol. 65, Issue 1, 2014, pp. 21-26.

[19] Lorincová, S., Hitka, M., Cambál, M., Szabó, P., Javorcíková, J. Motivational factors influencing senior managers in the forestry and wood-processing sector in Slovakia. BioResources, 2016, Vol. 11, Issue 4, pp. 10339-10348.

[20] Bajec, P., Tuljak-Suban, D. Selecting a Logistics Service Provider: A Definition of Criteria that Consider the Requirements of an External Competitive Environment. Transport Problems, 2017, Vol. 12, pp. 158-168. ISSN 1896-0596. DOI: 10.20858/tp.2017.12.se.14

[21] Lorincová, S., Schmidtová, J., Javorčíková, J. Employee job satisfaction in furniture manufacturing companies in the Slovak Republic. Drvna Industrija, 2016, Vol. 67, No. 4, pp. 351-362. https://doi.org/10.5552/drind.2016.1614

[22] Stacho, Z., Potkány, M., Stachová, K., Marcineková, K. The Organizational Culture as a Support of Innovation processes' Management. International Journal for Quality Research, 2017, Vol. 10, No. 4, pp. 769-784. ISSN 1800-6450.

[23] Gejdoš, M., Danihelová, Z. Valuation and timber market in the Slovak Republic. Procedia Economics and Finance, 2015, Vol. 34. pp. 697-703. https:// doi.org/10.1016/S2212-5671(15)01688-3

[24] Hockicko, P., Kristak, L., Nemec, M. Development of students' conceptual thinking by means of video analysis and interactive simulations at technical universities. European Journal of Engineering Education, 2015, Vol. 40, No. 2, pp. 145-166.https://doi.org/10.1080/03043797.2014.941337

[25] Mura, L, Horvath, P. Some aspects of human resource management International Multidisciplinary Scientific Conferences on Social Sciences and Arts. Albena, Bulgaria, 2015, pp. 863-870.

[26] Dorčák, P., Pollák, F. Distribution and internet. Logi - Scientific Journal on Transport and Logistics, 2011, Vol. 2, No. 2, pp. 5-13. ISSN 1804-3216.

[27] Němec, F., Hitka, M., Lorincová, S., Turínská, L. The storage area market in the particular territory. Nase More, 2015, Vol. 62. pp. 131-138. https://doi. org/10.17818/NM/2015/SI8

[28] Potkány, M., Hitka, M. Utilization of contribution margin in the costing system in production of components for wood working machines. Drvna Industrija, 2009, Vol. 60, Issue 2. pp. 101-110.

[29] Klewski, A., Sanecki, J., Pokonieczny, K., Stępień, G., Beczkowski, K. The method of processing of rapidly changing data for the inventory of flood effects purposes. Scientific Journals of the Maritime University of Szczecin, 2013, Vol. 33, No. 105, pp. 40-45. ISSN 1733-8670. 